\title{
SIMULASI SEBARAN SEDIMEN TERHADAP KETINGGIAN GELOMBANG DAN SUDUT DATANG GELOMBANG PECAH DI PESISIR PANTAI
}

\author{
Dian Savitri *)
}

\begin{abstract}
Abstrak
Gerakan air di daerah pesisir pantai merupakan kombinasi dari gelombang dan arus. Gelombang lebih bersifat melepas material didasar dan mengaduknya, sementara arus lebih bersifat memindahkan material sedimen ketempat lain. Jika dasar laut terdiri dari material yang mudah bergerak maka arus dan gelornbang akan mengerosi sedimen dan membawanya searah dengan arus. Untuk mengurangi dampak lingkungan dan memberikan manfaat bagi penduduk masih membutuhkan penelitian dan kajian lebih lanjut yang membutuhkan waktu dan biaya besar, sehingga upaya terbaik yang digunakan adalah pendekatan analisis sistem dengan simulasi untuk memprediksi besar sedimentasi yang terjadi.

Kajian awal makalah ini adalah untuk mengetahui bagaimana sebaran sedimen dengan cara memprediksi besar angkut sedimen terhadap ketinggian gelombang dan sudut datang gelombang pecah yang terjadi sepanjang pantai menggunakan simulasi Matlab. Hasil simulasi besar angkut sedimen diharapkan dapat memberikan gambaran sebaran besar angkut sedimen yang digunakan sebagai salah satu upaya mengurangi laju erosi dan sedimentasi yang terjadi di pesisir pantai
\end{abstract}

Kata Kunci: Simulasi, Sedimentasi, Gelombang Dan Pantai

\section{PENDAHULUAN}

Pada daerah pesisir pantai gerakan air merupakan kombinasi dari gelombang dan arus. Jika dasar laut terdiri dari material yang mudah bergerak maka arus dan gelornbang akan mengerosi sedimen dan membawanya searah dengan arus. Besar angkut sedimen sepanjang pantai banyak menyebabkan permasalahan seperti pendangkalan pelabuhan, erosi pantai dan sebagainya. Oleh karena itu perhitungan dan prediksi sebaran sedimen sepanjang pantai sangat penting untuk dilakukan. Beberapa cara yang digunakan untuk memprediksi sebaran sedimen sepanjang pesisir pantai dapat dilakukan dengan simulasi. Upaya ini merupakan salah satu langkah awal yang penting dilakukan mengingat penelitian dan kajian tentang sedimentasi masih membutuhkan waktu dan biaya yang besar.

Menurut Van Rijn (1993) besar angkut sedimen di pesisir pantai dipengaruhi oleh kombinasi faktor - faktor hidrodinamik seperti angin, gelombang dan arus. Sedangkan menurut Triadmodjo (1999) besar angkut sedimen secara fisik dipengaruhi oleh interaksi antara pasang surut, angin, arus, gelombang, jenis dan ukuran sedimen, serta adanya bangunan didaerah pantai (litoral zone). Besar angkut sedimen pesisir pantai terdiri dari dua komponen utama yaitu: besar angkut sedimen dalam bentuk mata gergaji di garis pantai dan besar angkut sedimen sepanjang pantai di surf zone. Pada waktu gelombang menuju pantai dengan membentuk sudut terhadap garis pantai maka gelombang tersebut akan naik ke pantai yang juga membentuk sudut. Massa air yang naik tersebut kemudian turun lagi dalam arah tegak lurus pantai. Gerak air tersebut membentuk lintasan seperti mata gergaji yang disertai dengan terangkutnya sedimen dalam arah sepanjang pantai. Komponen kedua adalah besar angkut sedimen yang ditimbulkan arus sepanjang pantai yang dibangkitkan oleh gelombang pecah yang terjadi di surf zone.

\section{Permasalahan}

Permasalahan makalah ini adalah bagaimana mengetahui sebaran sedimen terhadap ketinggian gelombang dan sudut datang gelombang pecah yang terjadi di pesisir pantai?

\section{Tujuan}

Tujuan makalah ini adalah mengetahui bagaimana sebaran sedimen dengan cara memprediksi besar angkut sedimen terhadap ketinggian gelombang dan sudut datang gelombang pecah yang terjadi sepanjang pantai menggunakan simulasi Matlab.

\footnotetext{
*) Dosen Fakultas Teknik Sipil Universitas Negeri Surabaya
} 


\section{KAJIAN PUSTAKA}

\section{A. Sedimen}

Sedimen yang terendap pada suatu daerah mempunyai beberapa manfaat bagi kehidupan, antara lain dapat digunakan sebagai bahan konstruksi, bahan coastal restoration dan sebagai tempat berkembang biak beberapa spesies air. Sedimen yang terlalu sedikit dapat menyebabkan kerusakan lingkungan. Terlalu banyaknya sedimen juga dapat mengakibatkan kerusakan lingkungan dan kerugian ekonomis, hal ini dicontohkan pada pelabuhan yang mengalami sedimentasi dapat mengakibatkan pendangkalan, kapal kesulitan keluar masuk pelabuhan, dan kapal harus mengurangi muatan agar tidak kandas.

Sedimen, yang tersusun dari batuan, mineral, dan material organik, secara alamiah selalu ada dalam sungai, danau, pantai, dan air laut. Sedimen adalah tanah dan bagian-bagian tanah yang terangkut dari suatu tempat yang tererosi. Sedimen ini terbawa aliran air dari satu tempat ke tempat yang lain sampai mengendap pada lokasi tertentu. Sedimen yang dihasilkan dari proses erosi dan terbawa suatu aliran akan diendapkan di suatu tempat yang kecepatan airnya melambat atau berhenti disebut dengan sedimentasi (Arsyad 2000). Menurut Asdak (2004), sedimen adalah hasil proses erosi baik berupa erosi permukaan, erosi parit atau jenis erosi tanah lainnya. Sedimen umumnya mengendap di bagian bawah bukit, di daerah genangan banjir, di saluran air, sungai, dan waduk. Proses sedimentasi dapat memberikan dampak yang menguntungkan dan merugikan. Dikatakan menguntungkan karena pada tingkat tertentu adanya aliran sedimen ke daerah hilir dapat menambah kesuburan tanah serta terbentuknya tanah garapan baru di daerah hilir. Tetapi, saat yang bersamaan aliran sedimen dapat menurunkan kualitas perairan dan pendangkalan badan perairan (Asdak 2004).

Linsey et. al (1989) dalam Salwati (2004) juga menyatakan bahwa produksi sedimen tahunan rata-rata dari suatu daerah aliran sungai tergantung dari banyak faktor seperti: iklim, jenis tanah, tata guna lahan, topografi, dan waduk. Faktor lain yang mempengaruhi besarnya sedimen yang masuk ke sungai menurut Asdak (2004) adalah karateristik sungai yang meliputi: morfologi sungai, tingkat kekasaran sungai, dan kemiringan sungai.

\section{B. Perhitungan besar angkut sedimen}

Besar angkut sedimen sepanjang pantai banyak menyebabkan permasalahan seperti pendangkalan pelabuhan, erosi pantai dan sebagainya. Oleh karena itu perhitungan dan prediksi besar angkut sedimen sepanjang pantai sangat penting untuk dilakukan. Salah satu cara yang digunakan untuk memprediksi sebaran dari besar angkut sedimen sepanjang pantai adalah menggunakan rumus empiris terhadap ketinggian gelombang dan sudut datang gelombang pecah di daerah pesisir pantai.

Prediksi besar angkut sedimen yang digunakan pada makalah ini beserta perhitungan besar angkut sedimen adalah menerapkan rumus untuk menghitung besar angkut sedimen sepanjang pantai yang dikembangkan berdasarkan data pengukuran model dan prototipe pada pantai berpasir.

Rumus yang digunakan:

$$
\begin{aligned}
& P 1=\frac{\rho g}{8} H_{b}{ }^{2} C_{b} \sin \alpha_{b} \cos \alpha_{b} \\
& Q s=K P 1^{n}
\end{aligned}
$$

Ichikawa mendekatinya dengan:

$$
\begin{aligned}
Q s= & 0.13 P_{1}^{-0.54} \\
\text { Dimana } & \\
\mathrm{Qs}= & \text { Besar angkut sedimen pesisir pantai } \\
& \left(\mathrm{m}^{3} / \text { hari }\right) \\
\mathrm{P} 1= & \text { Komponen fluk energi gelombang } \\
& \text { pesisir pantai saat pecah }(\mathrm{Nm} / \mathrm{d} / \mathrm{m}) \\
\rho= & \text { rapat massa air laut }\left(\mathrm{kg} / \mathrm{m}^{3}\right) \\
\mathrm{H}_{\mathrm{b}}= & \text { Tinggi gelombang pecah }(\mathrm{m}) \\
\mathrm{C}_{\mathrm{b}}= & \text { cepat rambat gelombang pecah }(\mathrm{m} / \mathrm{d}) \\
& =(\mathrm{g} \times \mathrm{db})^{0.5} \text { dimana db diambil } 0.78 \\
& \mathrm{H}_{\mathrm{b}} . \\
\alpha_{\mathrm{b}}= & \text { sudut gelombang pecah }
\end{aligned}
$$

\section{Model Matematis}

Model matematis dari prediksi sebaran sedimen akan melibatkan persamaan besar angkut sedimen sepanjang pantai yang terhadap sudut datang gelombang pecah dan ketinggian gelombang di daerah pesisir pantai. Salah satu upaya dalam perekayasaan adalah memprediksikan sebaran dari besar angkut sedimen yang terjadi. Untuk itu, diperlukan adanya suatu model yang dapat mensimulasikan sebaran 
besar angkut sedimen. Model yang diperlukan dapat berupa model fisik dan model numerik. Dibandingkan dengan model fisik, model numerik lebih praktis dan luwes, sebab parameter-parameter yang berpengaruh dapat secara mudah diubahubah sesuai skenario simulasi.

\section{Matlab}

Matlab adalah bahasa pemrograman dengan performa tingkat tinggi untuk memecahkan masalah yang menyangkut analisa perhitungan, baik secara analitik maupun numerik, dimana dalam mencari solusi dari analisis tersebut merupakan masalah yang sering dijumpai tidak saja pada bidang teknik, namun juga pada bidang lainnya seperti bidang ekonomi, matematika, fisika dan lain-lain.

Adapun kelebihan dari Matlab terhadap bahasa pemrograman lainnya adalah kemudahan dalam pendefinisian matriks, penurunan persamaan dan fungsifungsi dengan jumlah cukup banyak. Dengan memanfaatkan kelebihan dari software Matlab, maka efisiensi dalam pembuatan software akan meningkat. Adapun software Matlab yang digunakan adalah Matlab versi 6.5. Pada permasalahan perpindahan panas ini, software Matlab digunakan untuk penyelesaian perhitungan matriks dengan ukuran besar dan simulasi hasil yang didapat sampai terbentuk grafik perpindahan panas berupa kontur.

\section{PEMBAHASAN DAN SIMULASI}

\section{A. Simulasi}

Simulasi yang dilakukan pada makalah ini dapat memberikan gambaran bagaimana perubahan besar angkut sedimen di sepanjang pantai. Diharapkan dari hasil simulasi ini dapat dijadikan dasar dalam pemodelan sistem dari daerah tertentu yang ditinjau selama kurun waktu tertentu, sehingga dapat diketahui daerah-daerah kritis (daerah yang mengalami gerusan terbesar) dan dapat segera dilakukan penanganan dan antisipasi agar tidak sampai terjadi keadaan yang lebih mengkhawatirkan serta dapat digunakan sebagai salah satu solusi dalam upaya mengurangi laju erosi dan sedimentasi untuk mengendalikan erosi.

Ruang lingkup pembahasan pada makalah ini dibatasi hanya gambaran berupa grafik sebaran besar angkut sedimen dengan melakukan simulasi terhadap parameter ketinggian gelombang dan sudut datang gelombang pecah.

\section{B. Pembuatan Program}

Pembahasan dalam makalah ini adalah mengetahui sebaran besar angkut sedimen sepanjang pantai berdasarkan kondisi gelombang menggunakan rumus yang telah ada dengan pendekatan Ichikawa melalui pembuatan program (software) Matlab serta simulasi bagaimana sebaran besar angkut sedimen pada ketinggian gelombang yang berbeda serta kondisi beberapa sudut tang dibentuk oleh gelombang pecah yang terjadi.

Langkah pertama yang dilakukan dalam pembuatan program menggunakan Matlab adalah:

a. Menyusun M - File

Variabel - variabel yang digunakan:

qs = Besar angkut sedimen sepanjang pantai per hari yaitu $\mathrm{m}^{3} /$ hari

p1 = Komponen fluk energi gelombang sepanjang pantai saat pecah $(\mathrm{Nm} / \mathrm{d} / \mathrm{m})$

$\rho$ (pro) $=$ rapat massa air laut yang digunakan $1020 \mathrm{~kg} / \mathrm{m}^{3}$

$\mathrm{hb}=$ Tinggi gelombang pecah yaitu $\mathrm{m}$

$\mathrm{cb}=$ cepat rambat gelombang pecah $(\mathrm{m} / \mathrm{d})$

alpha = sudut datang gelombang pecah

$\mathrm{g}=$ percepatan gravitasi yang digunakan adalah 9,81

$\mathrm{db}=$ kedalaman air laut tepat terjadinya gelombang pecah diambil $0.78 \times \mathrm{hb}$

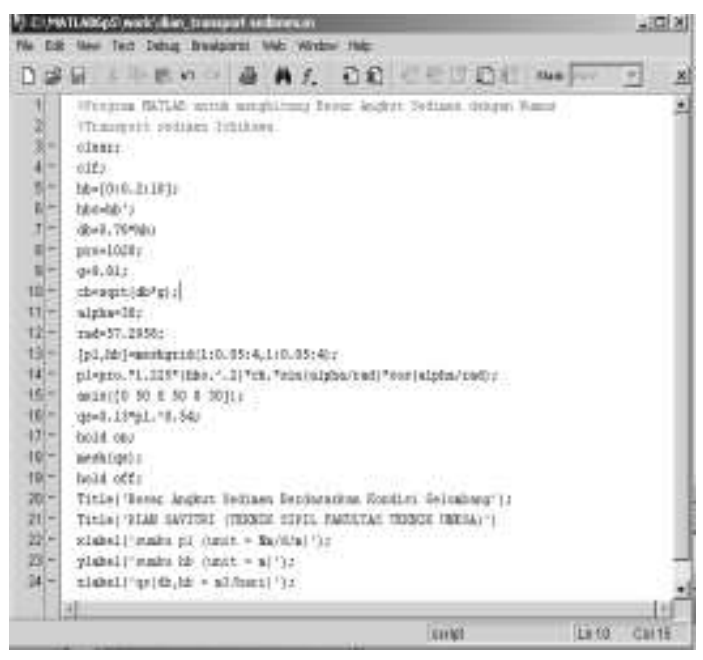

Gambar 1. Program perhitungan besar angkut sedimen dengan Matlab 
b. Running $\mathrm{M}-$ File

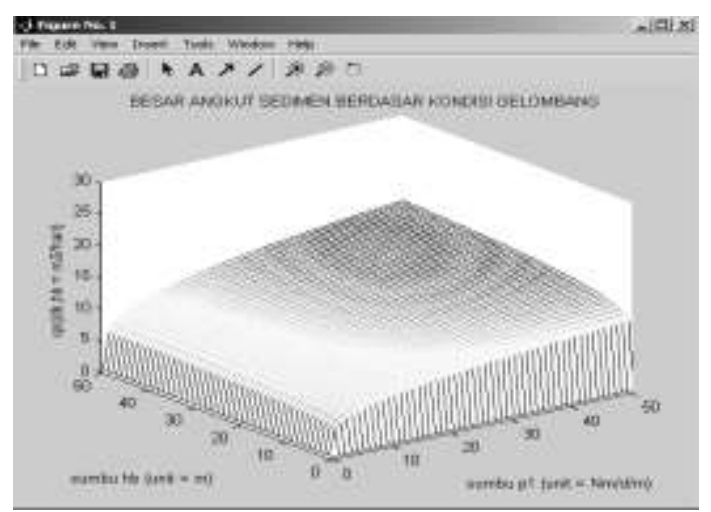

Gambar 2. Tampilan Program Simulasi Matlab

Hasil simulasi menggunakan Matlab terhadap besar angkut sedimen terhadap parameter ketinggian gelombang tiap hari serta sudut datang gelombang pecah yang diinformasikan melalui titik (node-node) pada jaringan elemen hingga berupa mesh. Pada makalah ini, hanya ditampilkan grafik yang memberikan gambaran pola sebaran besar angkut sedimen yang terjadi tiap hari.

\section{Simulasi program Matlab}

Simulasi program angkutan sedimen menggunakan Matlab versi 6.5 dilakukan berhadap sudut datang gelombang pecah, yaitu saat $\alpha=30^{\circ}, \alpha=45^{\circ}$ dan $\alpha=60^{\circ}$ serta kondisi ketinggian gelombang yang berbeda beda, yaitu saat ketinggian 5 meter, 10 meter, 20 meter, 40 meter serta 60 meter. Dalam makalah ini, dilakukan input parameter sedimen yang sesuai dengan data-data hasil tinjauan pustaka dari beberapa literatur.

a. Sudut datang gelombang pecah $\alpha=30^{\circ}$

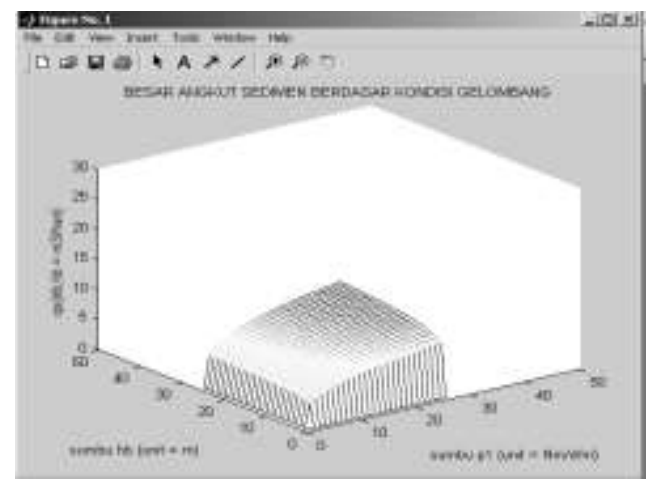

Gambar 3. Ketinggian gelombang 5 meter

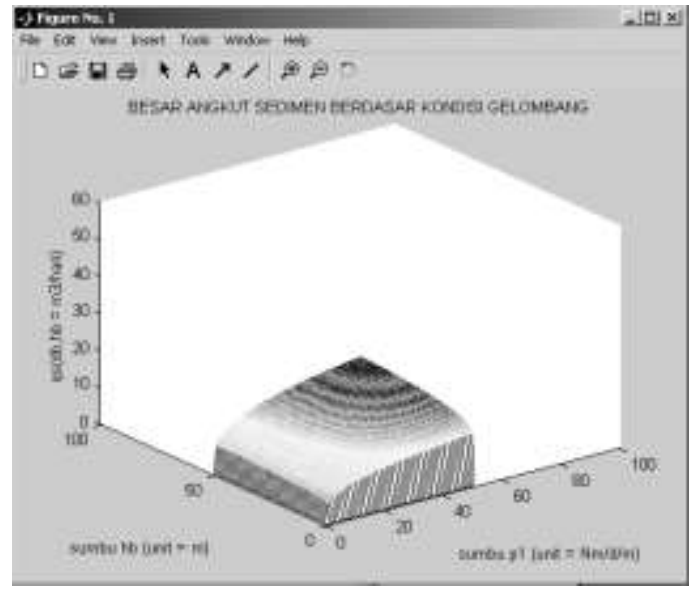

Gambar 4. Ketinggian gelombang 20 meter

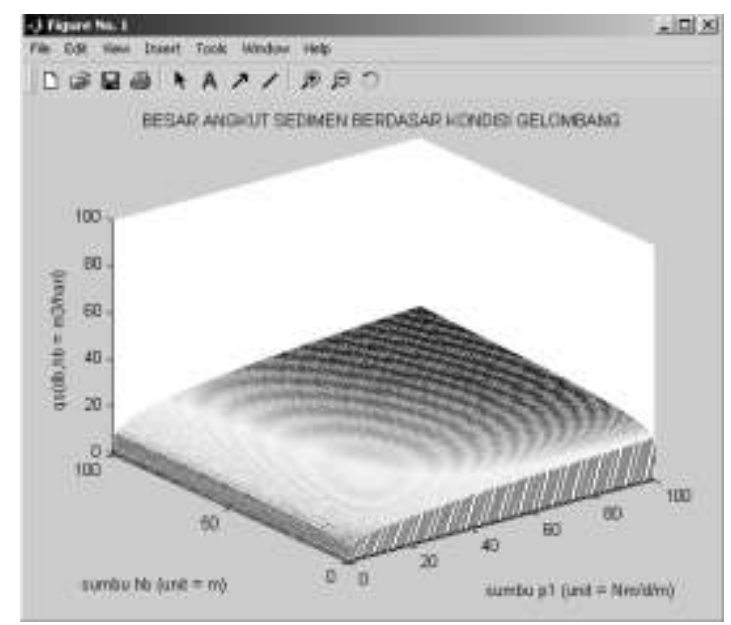

Gambar 5. Ketinggian gelombang 40 meter

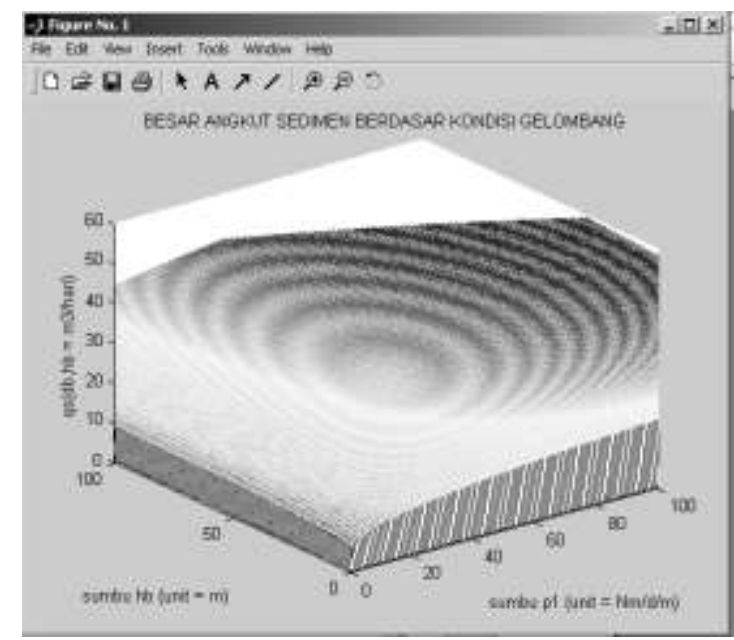

Gambar 6. Ketinggian gelombang 60 meter 
b. Sudut datang gelombang pecah $\alpha=45^{0}$

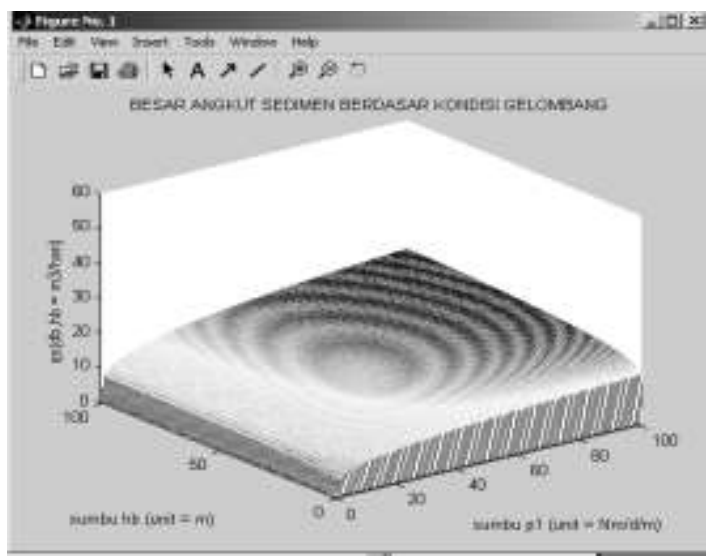

Gambar 7. Ketinggian gelombang 20 meter

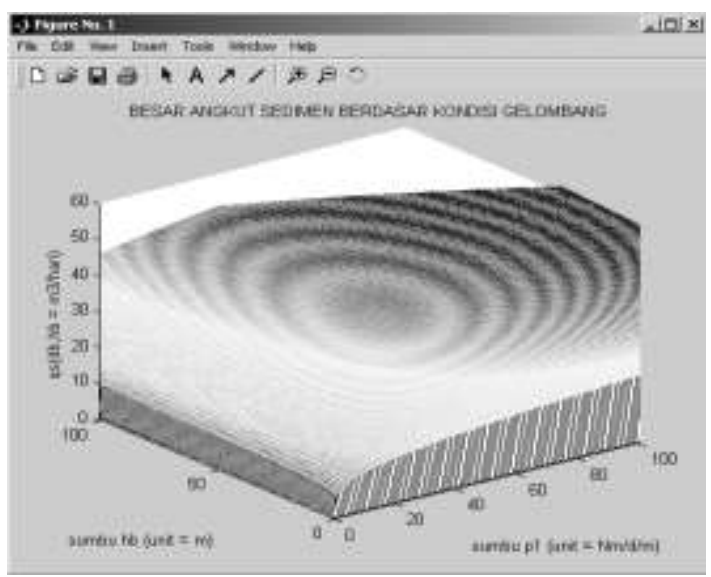

Gambar 8. Ketinggian gelombang 60 meter

c. Sudut datang gelombang pecah $\alpha=60^{\circ}$

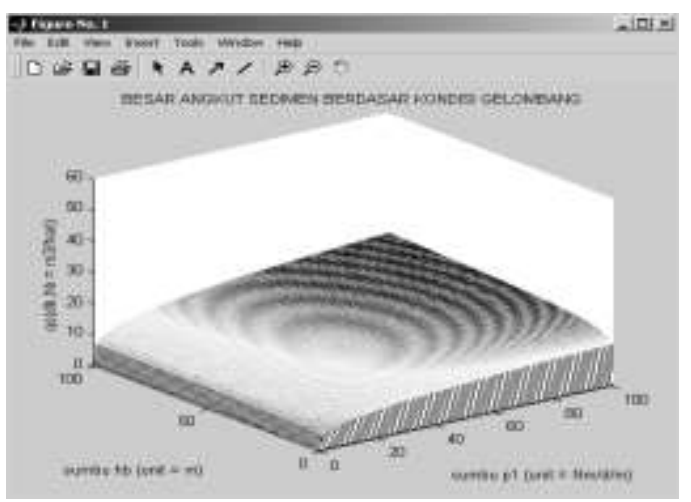

Gambar 9. Ketinggian gelombang 20 meter

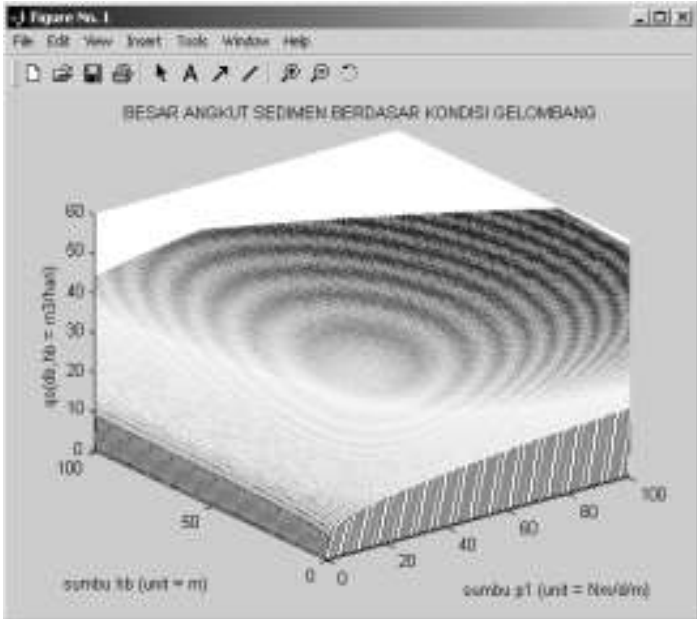

Gambar 10. Ketinggian gelombang 60 meter

\section{SIMPULAN}

Simpulan dari makalah ini adalah:

1. Hasil simulasi menggunakan Matlab versi 6.5 berupa sebaran besar angkut sedimen tiap hari yang diinformasikan melalui titik pada jaringan elemen hingga dalam bentuk mesh berhadap sudut datang gelombang pecah, yaitu $\alpha=30^{\circ}, \alpha=45^{\circ}$ dan $\alpha=60^{\circ}$ serta ketinggian gelombang berbeda beda, yaitu ketinggian 5 meter, 10 meter, 20 meter, 40 meter serta 60 meter.

2. Hhasil simulasi sebaran sedimen ini diharapkan dapat dijadikan dasar dalam pemodelan sistem dari daerah tertentu sehingga dapat diketahui daerah-daerah kritis sebagai salah satu upaya mengurangi laju erosi dan sedimentasi yang terjadi terutama di daerah pesisir pantai. 


\section{DAFTAR PUSTAKA}

Arsyad, S., 2000. Konservasi Tanah dan Air. Penerbit IPB (IPB Press), Bogor

Asdak, C., 2004. Hidrologi dan Pengelolaan Daerah Aliran Sungai. Gadjah Mada University Press, Yogyakarta.

BOSS SMS. 1995. User's Manual Boss SMS. Version 5.02. Engineering Computer Graphics Laboratory. Madison: Brigham Young University.

Chow, V. T., 1959, Open Channel Hydraulics, Mc. Graw Hill Kogakusha, Ltd., Tokyo.

Suroso, A. 1999. Model Perubahan Dasar. Tesis S2 Program Studi Teknik Sipil. Universitas Gadjah Mada Yogyakarta.

Sujatmoko. Bambang., 2006, Prediksi Perubahan Bentuk Dasar Sungai Di Belokan.

Triatmodjo, B. 1999. Teknik Pantai. Yogyakarta : Beta Offset.

Triatmodjo, B. 1996. Pelabuhan. Yogyakarta : Beta Offset.

Van Rijn, Leo C. 1993. Principles of Fluid Flow dan Surface Waves in Rivers, Estuaries, Seas, and Ocean. Aqua publication. Netherland 